\title{
MULTIFUNCTIONAL SURFACES WITH BIOMIMETIC NANOFIBRES AND DRUG-ELUTING MICRO-PATTERNS FOR INFECTION CONTROL AND BONE TISSUE FORMATION
}

\author{
X.N. Chen ${ }^{1}$, Y.X. Gu², J.H. Lee ${ }^{2}$, W.Y. Lee ${ }^{2}$ and H.J. Wang ${ }^{1, *}$
}

${ }^{1}$ Chemistry, Chemical Biology and Biomedical Engineering, ${ }^{2}$ Chemical Engineering and Materials Science, Stevens Institute of Technology, Hoboken, NJ 07030, USA

\begin{abstract}
For long-term orthopaedic implants, the creation of a surface that is repulsive to bacteria while adhesive to tissue cells represents a promising strategy to control infection. To obtain such multifunctional surfaces, two possible approaches were explored to incorporate a model antibiotic, rifampicin (Rf), into the osteogenic polycaprolactone (PCL)/chitosan (CHS) biomimetic nanofibre meshes by (1) blending Rf into the electrospinning solutions and then electrospinning into nanofibres (i.e., Rf-incorporating fibres), or (2) depositing Rf-containing poly(D,L-lacticco-glycolic) acid (PLGA) micro-patterns onto the PCL/ chitosan nanofibre meshes via ink-jet printing (i.e., Rfeluting micro-pattern/fibre). Rapid release of $\mathrm{Rf}$ from both meshes was measured even though a relatively slower release rate was obtained from the Rf-eluting micro-pattern ones. Antibacterial assay with Staphylococcus epidermidis showed that both mesh surfaces could effectively kill bacteria and prevent biofilm formation. However, only Rf-eluting micro-pattern meshes favoured the attachment, spreading and metabolic activity of preosteoblasts in the cell culture study. Furthermore, the Rf-eluting micro-pattern meshes could better support the osteogenic differentiation of preosteoblasts by up-regulating the gene expression of bone markers (type I collagen and alkaline phosphatase). Clearly, compared to Rf-incorporating nanofibre meshes, Rf-eluting micro-patterns could effectively prevent biofilm formation without sacrificing the osteogenic properties of $\mathrm{PCL} /$ chitosan nanofibre surfaces. This finding provides an innovative avenue to design multifunctional surfaces for enhancing bone tissue formation while controlling infection.
\end{abstract}

Keywords: Biomimetic nanofibres; drug-eluting micropatterns; infection control; osteogenesis.

* Address for correspondence:

Hongjun Wang

Department of Chemistry, Chemical Biology and

Biomedical Engineering,

Stevens Institute of Technology,

McLean Building Room 416,

1 Castle Point on Hudson, Hoboken, NJ 07030, USA

Telephone Number: +1 2012165556

FAX Number: +1 2012168240

E-mail: Hongjun.Wang@stevens.edu

\section{Introduction}

Infection control on abiotic surfaces remains a longstanding challenge, which becomes particularly important considering that infection is one of the leading causes of orthopaedic implant failure (Campoccia et al., 2006). Continuous innovation has been made to modify material surfaces for preventing bacterial colonisation, e.g., by grafting polyethylene glycol or other hydrophilic molecules to minimise bacterial adhesion (Bearinger et al., 2003; Banerjee et al., 2011), or incorporating antibiotics into implant materials or coating layers for controlled release to kill bacteria (Lucke, 2003; Alt et al., 2006; Radin and Ducheyne, 2007). While their efficiency in infection control has been demonstrated, there is no obvious evidence to show that these approaches would promote tissue growth. Tissue-integration with implant surface is not required for those implants for the temporary fracture fixation (Hayes et al., 2009; Moriarty et al., 2009; Hayes et al., 2010; Moriarty et al., 2010; Hayes et al., 2012); however, it becomes highly crucial for long-term implants such as hip prostheses. It is recognised that the fate of long-term orthopaedic implants mainly depends on the surface race between successful osseointegration and unwanted biofilm formation (Gristina, 1987) and an ideal surface for such orthopaedic implants should be repulsive to bacteria while adhesive to bone tissue cells. Following this concept, efforts to modify the surface with differential functionality for preventing biofilm formation and promoting bone tissue formation will be of great benefit. Up to now, very limited progress has been made in designing such multifunctional surfaces. Seminal efforts were made to functionalise titanium substrates with covalently grafted chitosan, hyaluronic acid or their derivatives to suppress bacterial adhesion, while enhancing osseointegration with immobilised RGD peptides or growth factors (Shi et al., 2008; Shi et al., 2009; Hu et al., 2010). With promising evidence in reducing bacterial adhesion and enhancing osteogenesis, the involvement of two chemical modification steps in this approach could potentially complicate its application. Thus, more costeffective approaches are preferred.

Recently, electrospun fibre meshes have received great attention as growth substrates for various cells and tissues, due to the simple electrospinning setup and the possibility of forming fibres from a variety of polymers, and more importantly, their morphological and dimensional similarity to native extracellular matrix (ECM). The flexibility to incorporate various biomolecules into electrospun nanofibre allows the configuration of specific 
Fig. 1. Schematic illustration of the design of multifunctional surfaces with antibacterial rifampicin (Rf) either directly incorporated in the $\mathrm{PCL} /$ chitosan nanofibres (fibre incorporated Rf, i.e., REF) or embedded in PLGA micropatterns (micro-pattern incorporated Rf, i.e., EFRM). Red particles stand for Rf.

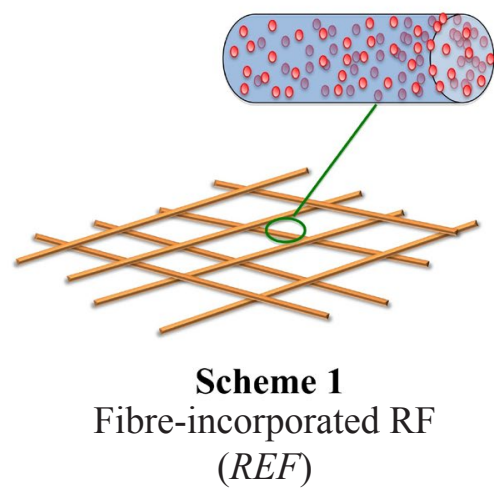

$(R E F)$

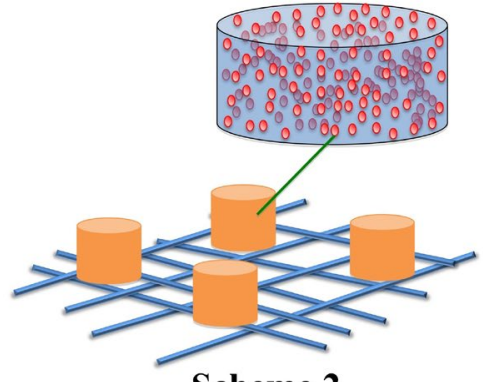

Scheme 2

Micro-pattern-incorporated RF $($ EFRM) substrates for desired tissue formation. For example, blending type I collagen into polycaprolactone (PCL) fibres can significantly improve the adhesion and growth of fibroblasts for soft tissue regeneration (Venugopal et al., 2006; Yang et al., 2009b). Our previous study has shown that PCL/chitosan composite fibres support the adhesion and proliferation of preosteoblasts and their osteogenic differentiation (Yang et al., 2009a).

In order to prevent infection, it is possible to include antifouling molecules or antimicrobial drugs into electrospun nanofibres (Kenawy et al., 2002; Katti et al., 2004; Kim et al., 2004). With the application mainly focused on antimicrobial effects or preventing postsurgery-induced abdominal adhesions (Bölgen et al., 2007; Zong et al., 2004), little attention was paid to their potential effects on tissue cells. It is known that nanofibres regulate cell adhesion by interacting with various cell membrane integrins to form focal adhesion plaques as a synergistic result of both fibre morphology and surface chemistry (Schindler et al., 2005; Yin et al., 2010), which in turn regulate the cell phenotype (Huang et al., 2012). The incorporation of such molecules in electrospun nanofibres would alter the surface properties and consequently lead to a differential cellular response. In this regard, we propose a novel strategy to introduce the antimicrobial function to electrospun nanofibre meshes while maintaining the osseointegration capacity of nanofibres. In this strategy, drug-eluting bioresorbable micro-patterns are created on the nanofibre mesh surfaces to release antimicrobial drugs that prevent bacterial colony formation. The micro-patterns can be produced with recent advances in "demand-ondrop" printing and patterning of nanocomposite materials via evaporative assembly, along with the significant progress in inkjet printing onto three-dimensional (3D) object surfaces with multi-axis robotics (Hamade et al., 2005). Thus, the aim of this study is to demonstrate the efficacy of electrospun PCL/chitosan nanofibre meshes with antibiotic-eluting micro-patterns in preventing infection while promoting osteogenesis. The hypothesis is that antibiotics incorporated into micro-patterns would not affect the behaviour of tissue cells on nanofibre surfaces and its release can effectively kill the bacteria.

In this study, rifampicin (Rf) was used as a model antibiotic for its potency in managing bone infection and its effectiveness against Staphylococci (O'Reilly et al., 1992; Zimmerli et al., 1998). Rf is often recommended to be used in combination with other antibiotics (Zimmerli et al., 2004) to achieve optimal efficacy and minimise the bacterial resistance (Shasha et al., 1994). However, our previous result showed that $\mathrm{Rf}$ alone was effective to kill planktonic S. epidermidis of NJ9709 strain (Lee et al., 2011), which was used as the bacterium model in this study. To prove the hypothesis and achieve the multifunctionality of the multi-scale surfaces, a periodic array of poly(D,L-lactic-co-glycolic) acid (PLGA) circular patterns $(\sim 75 \mu \mathrm{m}$ in diameter and $\sim 150 \mu \mathrm{m}$ apart between the centres of two adjacent micro-patterns) containing $\mathrm{Rf}$ were printed onto electrospun PCL/chitosan nanofibre meshes (Fig. 1). The Rf-containing PCL/chitosan nanofibre meshes (Fig. 1) were also included in the study for sideby-side comparison of the advantages of new multiscale surfaces. The capabilities of such Rf-incorporated surfaces in killing $S$. epidermidis bacteria and supporting osteogenesis of preosteoblasts were investigated. This finding would provide us with an innovative avenue to design multifunctional surfaces for both controlling infection and enhancing bone tissue formation, which can be used to improve the surface of permanent orthopaedic implants in the near term and prevent infection in tissueengineered grafts in the long run.

\section{Materials and Methods}

\section{Materials}

1,1,1,3,3,3-hexafluoro-2-propanol (HFIP) was obtained from Oakwood Products (West Columbia, SC, USA). Poly $(\varepsilon$-caprolactone) $(\mathrm{PCL}$, molecular weight $=80,000)$ and chitosan (CHS, medium molecular weight) were purchased from Sigma-Aldrich (St. Louis, MO, USA). Dimethyl sulphoxide (DMSO, $\geq 99 \%$ ) from Sigma-Aldrich was used as a solvent for PLGA (5050DLG3E, Mw 25,000, $50 \mathrm{wt} \%$ PLA, Lakeshore Biomaterials, Birmingham, AL, USA) and rifampicin (Rf) ( $\geq 97 \%$, Sigma-Aldrich). Foetal bovine serum (FBS) was purchased from the American Type Culture Collection (ATCC, Manassas, VA, USA). All other reagents and solutions were obtained from Invitrogen/Life Technologies (Carlsbad, CA, USA) except as indicated. 


\section{Electrospinning and characterisation}

Various nanofibres were prepared using established electrospinning techniques as described elsewhere (Yang et al., 2009a). To prepare PCL/chitosan nanofibre meshes (abbreviated as $E F)$, chitosan solution $(0.8 \mathrm{wt} \%)$ and PCL solution $(8 \mathrm{wt} \%)$ dissolved in HFIP were mixed thoroughly at a volume ratio of $1: 1$. These electrospun fibre $(E F)$ meshes were produced at a voltage of $15 \mathrm{kV}$ with a flow rate of $10 \mu \mathrm{L} / \mathrm{min}$ with Young's modulus as $16.0 \pm 1.4 \mathrm{MPa}$ (Yang et al., 2009a) and they were collected on square glass cover slips $(22 \mathrm{~mm} \times 22 \mathrm{~mm})$ for both bacterial and cell culture. To prepare Rf-containing electrospun fibres (abbreviated as $R E F), \operatorname{Rf}(0.73 \mathrm{wt} \%$ ) was dissolved in the 1:1 (v/v) PCL/chitosan solution and mixed thoroughly prior to electrospinning. To characterise the electrospun fibres, fibres collected on silicon ( $\mathrm{Si}$ ) wafers were sputter-coated with gold and then examined with a LEO 982 field emission gun (FEG) scanning electron microscope (SEM) (Zeiss, Oberkochen, Germany). To determine the fibre diameter, images of five randomly selected areas were captured and measured by analysis software (NIS-elements BR 3.10) from Nikon (Nikon Instruments Inc., Melville, NY, USA). To measure the surface chemistry of nanofibres, Fourier transform infrared (FTIR) spectra were obtained with a Jasco (Easton, MD, USA) FT/IR-460 plus spectrometer.

\section{Micro-pattern formation and characterisation}

Rf containing PLGA circular patterns were directly printed on the $1: 1(\mathrm{v} / \mathrm{v})$ PCL/chitosan nanofibre surface (abbreviated as EFRM) using a commercial inkjet printer (Dimatix Materials Printer, DMP2800, FUJIFILM Dimatix, Santa Clara, CA, USA) as described elsewhere (Gu et al., 2012). The printer utilises micro-fabricated piezoelectric nozzles for on-demand and programmable generation of $10 \mathrm{pL}$ droplets of jetting solutions with spatial resolution of $\sim 50 \mu \mathrm{m}$. Briefly, the jetting solution was prepared by dissolving PLGA (6 wt \%) and Rf(1 wt\%) in DMSO at $\sim 50{ }^{\circ} \mathrm{C}$ and stirring in the dark overnight. The prepared solution was transferred to the printer cartridge with a syringe and then ultrasonicated for $20 \mathrm{~min}$. The firing voltage, nozzle temperature, substrate temperature, nozzle-substrate distance, droplet spacing, and interlayer delay for the printing were set at $30 \mathrm{~V}, 35^{\circ} \mathrm{C}, 45^{\circ} \mathrm{C}$, $0.5 \mathrm{~mm}, 150 \mu \mathrm{m}$ and $90 \mathrm{sec}$, respectively. 20 layers of Rf-containing micro-patterns were printed on $E F$. To characterise the morphology and size of circular micropatterns, the collected samples were sputter-coated with gold and examined with SEM. Randomly selected images $(n=5)$ were used to measure the micro-pattern size and inter-pattern distance.

\section{Release kinetics of $\mathbf{R f}$}

To determine the antibiotic release, the amount of $\mathrm{Rf}$ per sample $(n=6)$ was accurately measured as $44.3 \pm 4.3 \mu \mathrm{g}$ for REF and $43.7 \pm 3.7 \mu \mathrm{g}$ for EFRM $(p>0.05)$, respectively. Then the samples were incubated in $2 \mathrm{~mL}$ phosphate buffered saline solution (PBS, $\mathrm{pH}=7.0$ ) at $37^{\circ} \mathrm{C}$ under shaking at $50 \mathrm{rpm}$. At designated time intervals, the supernatant was collected and immediately replenished with an equal amount $(2 \mathrm{~mL})$ of fresh PBS in an "infinite sink" release fashion. The average Rf concentration in the collected supernatant was determined by measuring the absorbance at $330 \mathrm{~nm}$ (Otto et al., 2008) using a Synergy ${ }^{\mathrm{TM}}$ HT multi-detection microplate reader (BioTek Instruments, Winooski, VT, USA). The UV absorbance of Rf was then converted to the concentration based on the obtained linear standard curve (Rf: $0-40 \mu \mathrm{g} / \mathrm{mL}, \mathrm{r}^{2}>0.997$ ). The measurement was performed at one-hour intervals for up to three days. The cumulative release of $\mathrm{Rf}$ at designated time was calculated. The percentage of total released $\mathrm{Rf}$ was calculated by dividing the cumulative amount of $\mathrm{Rf}$ in the supernatant by the total amount of Rf initially included in REF and EFRM.

\section{Bacterial culture}

Prior to testing, various substrates (EF, REF and EFRM, $n=6$ ) collected on glass cover slips were UV sterilised for $30 \mathrm{~min}$ in 6-well plates. An inoculum of $S$. epidermidis biofilm strain, NJ9709, obtained from the surface of an infected intravenous catheter, was prepared as described previously (Kaplan et al., 2004). The final inoculum was diluted in trypticase soy broth (TSB) medium at a final concentration of approximately $1 \times 10^{7}$ colony forming unit $(\mathrm{CFU}) / \mathrm{mL}$ as counted by the Petroff-Hausser counting chamber (Electron Microscopy Sciences, Hatfield, PA, USA) before inoculation and confirmed by agar plating the next day. $2 \mathrm{~mL}$ bacterium-containing TSB medium was added to each well. After culturing for 5 hours, the supernatant from each culture was collected and planktonic bacteria in the supernatant were analysed by agar plating $(n=3)$. At the end of culture, half of the samples $(n=3)$ were stained with a live/dead fluorescent staining kit (SYTO9 green and propidium iodide: BacLight ${ }^{\mathrm{TM}}$ Bacterial Viability Kit, Invitrogen/Life Technologies) for $15 \mathrm{~min}$ and then examined with a Nikon Eclipse $80 i$ fluorescent microscope (Nikon). The other half $(n=3)$ were stained with $0.75 \mathrm{wt} \%$ crystal violet for $5 \mathrm{~min}$ and then the stain was dissolved in $1 \mathrm{~mL}$ of $30 \%$ acetic acid. $200 \mu \mathrm{L}$ of the supernatant was transferred to a 96-well plate to measure the optical density (OD) using a Synergy HT multidetection microplate reader at $595 \mathrm{~nm}$.

\section{Osteoblastic cell culture}

Mouse preosteoblasts (MC 3T3-E1) from bone calvaria were cultured in $\alpha$-minimum essential medium ( $\alpha$-MEM) supplemented with $10 \% \mathrm{FBS}, 1 \%$ penicillin/streptomycin. The culture was maintained at $37^{\circ} \mathrm{C}$ with $5 \% \mathrm{CO}_{2}$ until $70-80 \%$ confluence prior to use.

\section{Cell metabolic activity}

The metabolic activity of MC 3T3-E1 on various substrates (REF, EFRM, and EF) was quantified by using the 3-(4, 5-dimethylthiazol-2-yl)-2, 5-diphenyl tetrazolium bromide (MTT) assay, which can be used to reliably measure cell metabolic activity in vitro for assessing cell growth (Sieuwerts et al., 1995). Briefly, after UV-sterilisation and medium incubation, the substrates $(n=3)$ were seeded with MC 3T3-E1 cells at a density of $5 \times 10^{4}$ cells per sample for overnight. Complete culture media ( $\alpha$-MEM supplemented with $10 \mathrm{mM} \beta$-glycerophosphate, $10^{-7} \mathrm{M}$ dexamethasone 
and $80 \mathrm{mg} / \mathrm{mL}$ ascorbic acid) was used to continuously culture for 1, 3 and 7 days. The culture was rinsed with PBS and then incubated with $\alpha$-MEM media containing $10 \%$ MTT solution ( $5 \mathrm{mg} / \mathrm{mL}$, Sigma-Aldrich) for $2 \mathrm{~h}$ at $37^{\circ} \mathrm{C}$. Then the unreacted MTT solution was discarded and the metabolically formed formazan was extracted with DMSO. $200 \mu \mathrm{L}$ of the extract was transferred to a 96-well plate and the absorbance was measured with the Synergy ${ }^{\mathrm{TM}}$ HT multi-detection microplate reader at $570 \mathrm{~nm}$.

\section{Cell morphology}

After culturing for one and three days, samples were fixed in $4 \%$ formaldehyde and permeabilised with $0.5 \%$ Triton X-100 in PBS. The cells were stained with TRITCconjugated-phalloidin (50 $\mu \mathrm{g} / \mathrm{mL}$ from Sigma-Aldrich) for $40 \mathrm{~min}$ at room temperature and then the cell nuclei were stained with DAPI in Vectashield mounting medium (Vector Lab, Burlingame, CA, USA). Stained cells were examined with a Nikon $80 i$ fluorescent microscope.

\section{Gene expression}

To compare the ability of various substrates (EF, REF and EFRM, $n=3$ ) to induce the osteogenesis of preosteoblasts, reverse transcriptase polymerase chain reaction (RT-PCR) was performed on the cultured cells for marker gene expression. Total RNA was isolated using the Multisource Total RNA Miniprep Kit (Axygen Biosciences, Union City, CA, USA) and then reverse-transcribed into complementary DNA (cDNA) using the SuperScript First-Strand Synthesis System (Promega, Madison, WI, USA). The cDNA product was then amplified using recombinant Taq DNA polymerase (Promega). Expressions of type I collagen (COL-1; sense, 5'-TCTCCACTCTTCTAGTTCCT-3'; antisense, 5'-TTGGGTCATTTCCACATGC-3', 269 bps), alkaline phosphatase (ALP; sense, 5'-GGGACTGGTACTCGGATAACGA-3'; antisense, 5'-CTGATATGCGATGTCCTTGCA-3', 71 bps) and osteopontin (OPN; sense, 5'-ATGAGATTGGCAGTGATTTG-3'; antisense, 5' - G TA G G G A C G A T T G G A G T G A - 3', $410 \mathrm{bps}$ ) were examined. $\beta$-actin (sense, 5'-AACCCTAAGGCCAACCGTG-3'; antisense, 5'-CAGGATTCCATACCCAAGAAG-3', 485 bps) served as the house-keeping gene control. All genes were amplified for 30 cycles in a thermocycler (Eppendorf
Mastercycler gradient, Brinkmann, Westbury, NY, USA). Semi-quantitative analysis of gene expression was performed, and band intensity was normalised to that of $\beta$-actin.

\section{Statistical analysis}

Each experiment was repeated at least 3 times on different days and data were expressed as the mean \pm standard deviation (SD). All the data were collected in triplicate for each group. The nonparametric approach was applied to statistically analyse the results by using SAS (SAS Institute, Cary, NC, USA) procedure NPAR1WAY (SAS 9.2). To test if there is any difference among the three types (EF, REF and EFRM), Kruskal-Wallis test (Exact) was performed. two-sided Wilcoxon Rank Sum test (Exact) was further used to conduct pairwise comparisons. Bonferroni adjustment was used to adjust $p$ values for multiple comparisons. A value of $p<0.05$ was considered statistically significant.

\section{Results}

Fabrication and characterisation of biomimetic substrates To prevent the colonisation of $S$. epidermidis, Rf, an active antibiotic was either directly incorporated into the PCL/ chitosan nanofibres while electrospinning (defined as $R E F$ in Fig. 1) or incorporated into PLGA micro-patterns that were deposited onto the PCL/chitosan nanofibre meshes (defined as EFRM in Fig. 1). Table 1 shows the composition and average fibre diameter for each substrate. PCL/chitosan nanofibre meshes without $\mathrm{Rf}$ were included as controls and the total $\mathrm{Rf}$ weight percentage remained constant (14.29\%) by maintaining the weight ratio of polymer to $\mathrm{Rf}$ at 6 to 1 for both REF and EFRM. Due to the intrinsic red colour of Rf, both REF and PLGA micro-patterns appeared to be orange (Fig. $2 \mathrm{~b}$ and $\mathrm{c}$ insets). Although the inclusion of Rf into PCL/chitosan electrospun nanofibres did not significantly change the average fibre diameter (Table 1) and fibre surface morphology (Fig. 2d and 2e insets), it caused non-uniform electrospun nanofibres as evidenced by bead formation (Fig. 2e). The surface chemistry of nanofibres was characterised by FTIR and signature peaks of Rf at approximately 1380 and $1460 \mathrm{~cm}^{-1}$ that corresponded to the stretching $\mathrm{C}=\mathrm{C}$ bonds of naphthalene

Table 1. Formulation and dimensions of various substrates.

\begin{tabular}{|c|c|c|}
\hline Material group & Composition & Dimension \\
\hline $\begin{array}{l}\text { EF: } \\
\text { electrospun fibres }\end{array}$ & $\begin{array}{l}\text { Electrospun PCL/chitosan nanofibrous mesh of } \\
\text { PCL:chitosan }=10: 1=4 \% \text { PCL: } 0.4 \% \text { chitosan }\end{array}$ & $\begin{array}{l}\text { Avg. fibre diameter }(\mathrm{nm}) \text { : } \\
\quad 404.0 \pm 207.8\end{array}$ \\
\hline $\begin{array}{l}\text { REF: } \\
\text { Rf-containing electrospun fibres, } \\
\text { Rf }=14.3 \mathrm{wt} \%\end{array}$ & $\begin{array}{l}\text { Electrospun PCL/chitosan nanofibrous mesh with Rf } \\
\text { PCL:chitosan:Rf }=60: 6: 11=4 \% \text { PCL: } 0.4 \% \\
\text { chitosan:0.7 \% Rf }\end{array}$ & $\begin{array}{l}\text { Avg. fibre diameter }(\mathrm{nm}) \text { : } \\
\quad 397.4 \pm 106.8\end{array}$ \\
\hline $\begin{array}{l}\text { EFRM: } \\
\text { electrospun fibres + Rf-containing } \\
\text { micro-patterns, } \mathrm{Rf}=14.3 \mathrm{wt} \%\end{array}$ & $\begin{array}{l}\text { Electrospun PCL/chitosan fibre mesh with PLGA/Rf } \\
\text { micro-patterns } \\
\text { PLGA:Rf }=6: 1=6 \% \text { PLGA: } 1 \% \text { Rf }\end{array}$ & $\begin{array}{c}\text { Avg. fibre diameter }(\mathrm{nm}): \\
404.0 \pm 207.8 \\
\text { Avg. micropattern }(\mu \mathrm{m}): \\
75.2 \pm 3.0\end{array}$ \\
\hline
\end{tabular}



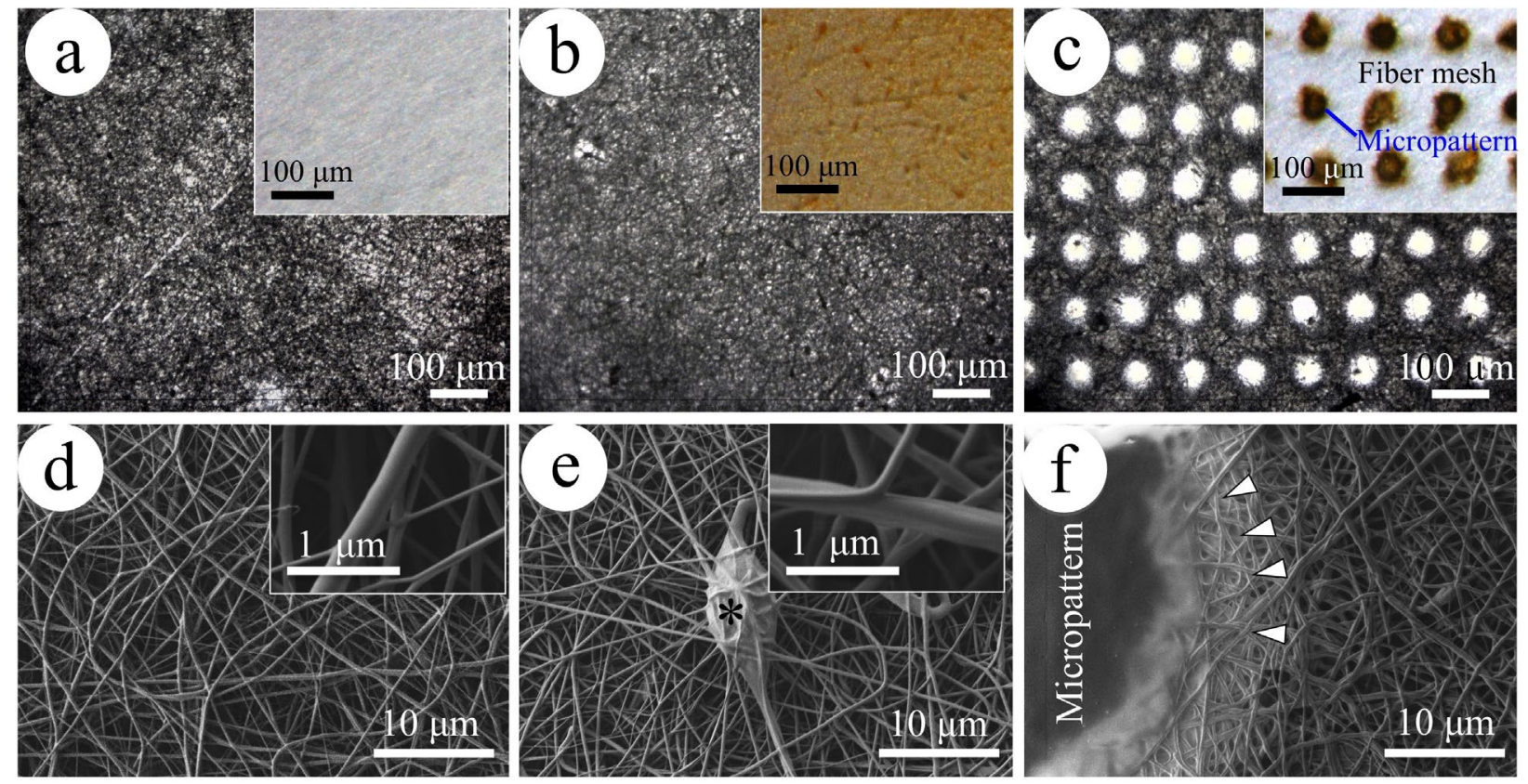

Fig. 2. Representative microscopic images of multifunctional biomimetic surfaces: EF (a, d), REF (b, e), and EFRM (c, f). Phase contrast optical images showed the surface morphology of various meshes and $50 \mu \mathrm{m}$ PLGA micro-patterns (a-c) and stereo microscopic images showed the colour of Rf-containing nanofibres and PLGA micropatterns (a-c inset). Scanning electron microscopic images showed the morphology of PCL/chitosan nanofibres (d), Rf-incorporating nanofibres (e) and the PLGA micro-patterns (f) and high magnification ( $\mathrm{d}$ and e inset). Asterisk in (e): beads formed during electrospinning. Arrows in (f): the bonding between micro-patterns and nanofibres. (a-c) and their insets: Scale bar $=100 \mu \mathrm{m} ;(\mathbf{d}-\mathbf{f})$ : scale bar $=10 \mu \mathrm{m}$ and their insets: scale bar $=1 \mu \mathrm{m}$.

ring and at $1545 \mathrm{~cm}^{-1}$ that corresponded to the stretching amide bond (Silverstein and Webster 1997) were observed on REF but not on EF meshes (Fig. 3). The deposition of Rf-containing micro-patterns, composed of arrays of dried Rf/PLGA droplets with $\sim 75 \mu \mathrm{m}$ in diameter (Fig. $2 \mathrm{c}$ and inset), onto PCL/chitosan nanofibre meshes did not affect the nanofibre morphology, while a tight bonding formed between the micro-patterns and the nanofibres (Fig. 2f).

\section{Controlled release of $\mathbf{R f}$}

The release of Rf from either REF or EFRM was performed in PBS (pH 7.0) at $37^{\circ} \mathrm{C}$ for up to three days with Rf-free $\mathrm{EF}$ as controls $(n=3)$. With a similar release pattern, i.e., an initial burst release and cumulative release over a period of three days, a faster release rate was measured in REF compared to EFRM (Fig. 4). After one-hour incubation, about $71.9 \%$ of the initially loaded Rf was released from REF, reaching $14.8 \mu \mathrm{g} / \mathrm{mL}$ in the supernatant. In comparison, about $41.7 \%$ of the initially loaded Rf was released from EFRM for a concentration of $8.6 \mu \mathrm{g} / \mathrm{mL}$ in the supernatant. After $24 \mathrm{~h}$, all Rf was released from REF, while $3.3 \%$ Rf still remained in the PLGA micro-patterns of EFRM and was completely released in another $24 \mathrm{~h}$. In both groups, the cumulatively released $\mathrm{Rf}$ drastically exceeded the minimal bactericidal concentration (MBC, $0.5 \mu \mathrm{g} / \mathrm{mL}$ ) (Monzon et al., 2001), sufficient to kill those S. epidermidis coming to the implant surface.

\section{Bacterial culture}

After $5 \mathrm{~h}$ bacterial culture, crystal violet staining showed that EF gave the most intense staining and EFRM the

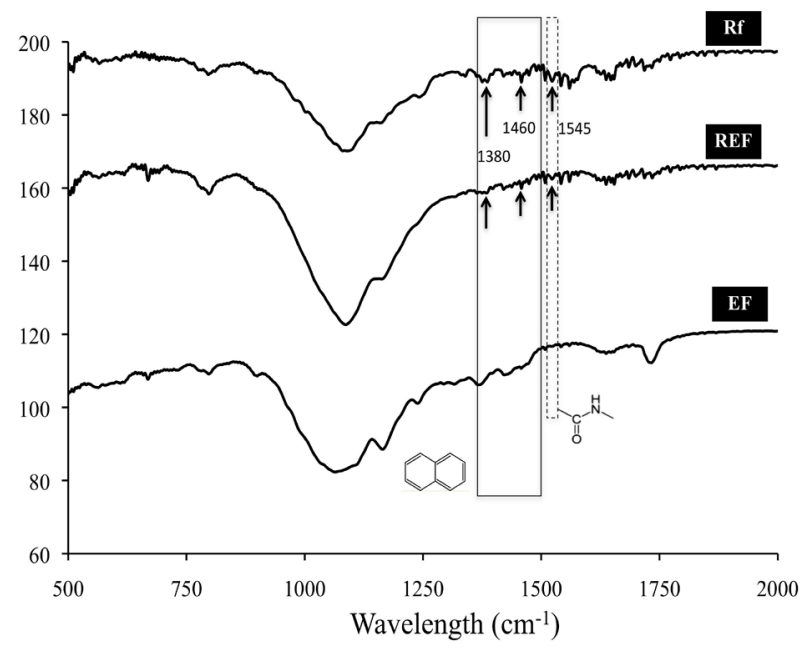

Fig. 3. Fourier transform infrared (FTIR) spectra of Rf, EF and REF.

lowest one, and there was no significant difference between EFRM and REF (Fig. 5a). Quantification of the staining by measuring the OD value of the extracts of crystal violet staining $(n=3)$ confirmed this observation, showing that the EF group stained approximately 6 times more than the REF group and 9 times more than the EFRM group (Fig. 5b). Close examination of the staining revealed the presence of only individual $S$. epidermidis cells in both REF and EFRM groups (white arrows in Fig. 5e and $f$ insets) in contrast to large purple clumps in the EF group (asterisk of Fig. 5d inset). The fluorescent live/dead 


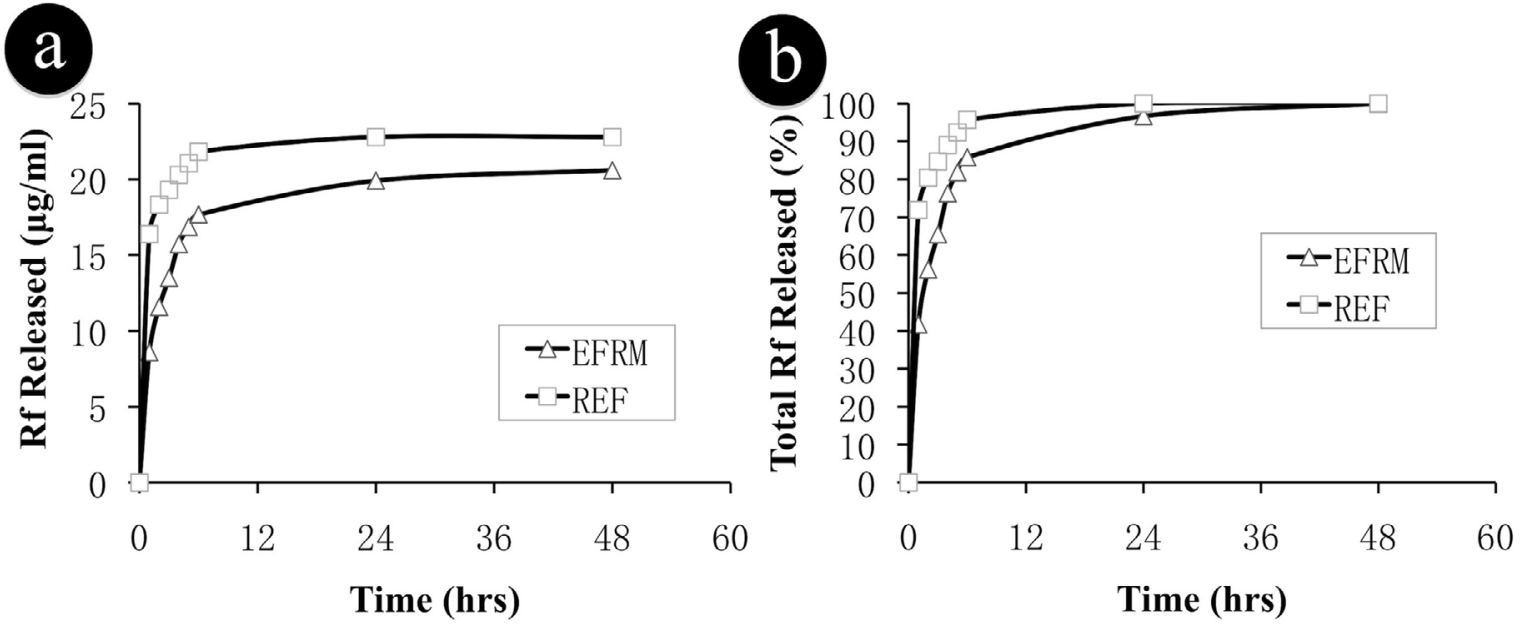

Fig. 4. Time-dependent release of Rf from REF or EFRM. Accumulative Rf concentration in the releasing buffer solution (a). Released RF as percentage of a total loaded (b).

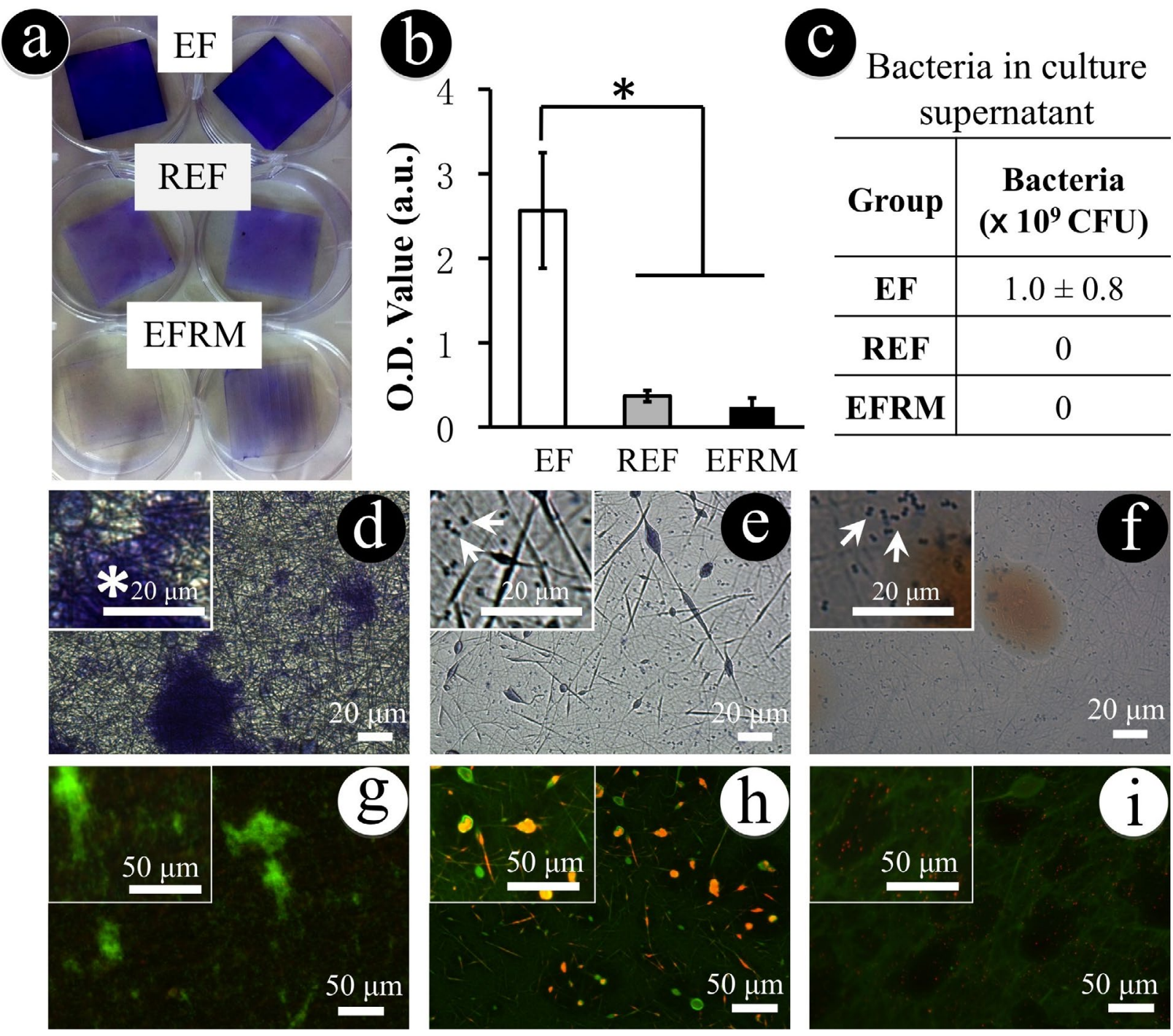

Fig. 5. Antibacterial activity of multifunctional surfaces. Representative optical images of various surfaces cultured with S. epidermidis for 5 hours and then stained with crystal violet (a). Quantification of the crystal violet-stained culture by measuring the optical density of the extracts (b). Quantification of S. epidermidis in the culture supernatants on various surfaces by agar plating (c). Optical images of various surfaces after crystal violet staining (d-f) and inset: high magnification. Asterisk in (d): bacterial mass; arrows in (e) and (f): individual bacterial cells. Fluorescent microscopic images of various surfaces after live/dead staining of the cultured S. epidermidis (g-i) and inset: high magnification. Green: live bacteria; red: dead bacteria. $\operatorname{EF}(\mathbf{d}, \mathbf{g}) ; \operatorname{REF}(\mathbf{e}, \mathbf{h}) ; \operatorname{EFRM}(\mathbf{f}, \mathbf{i})$. $*$ Statistically significant, $p<0.01$. (d-f) Scale bar $=20 \mu \mathrm{m} ;($ g-i) scale bar $=50 \mu \mathrm{m}$. 

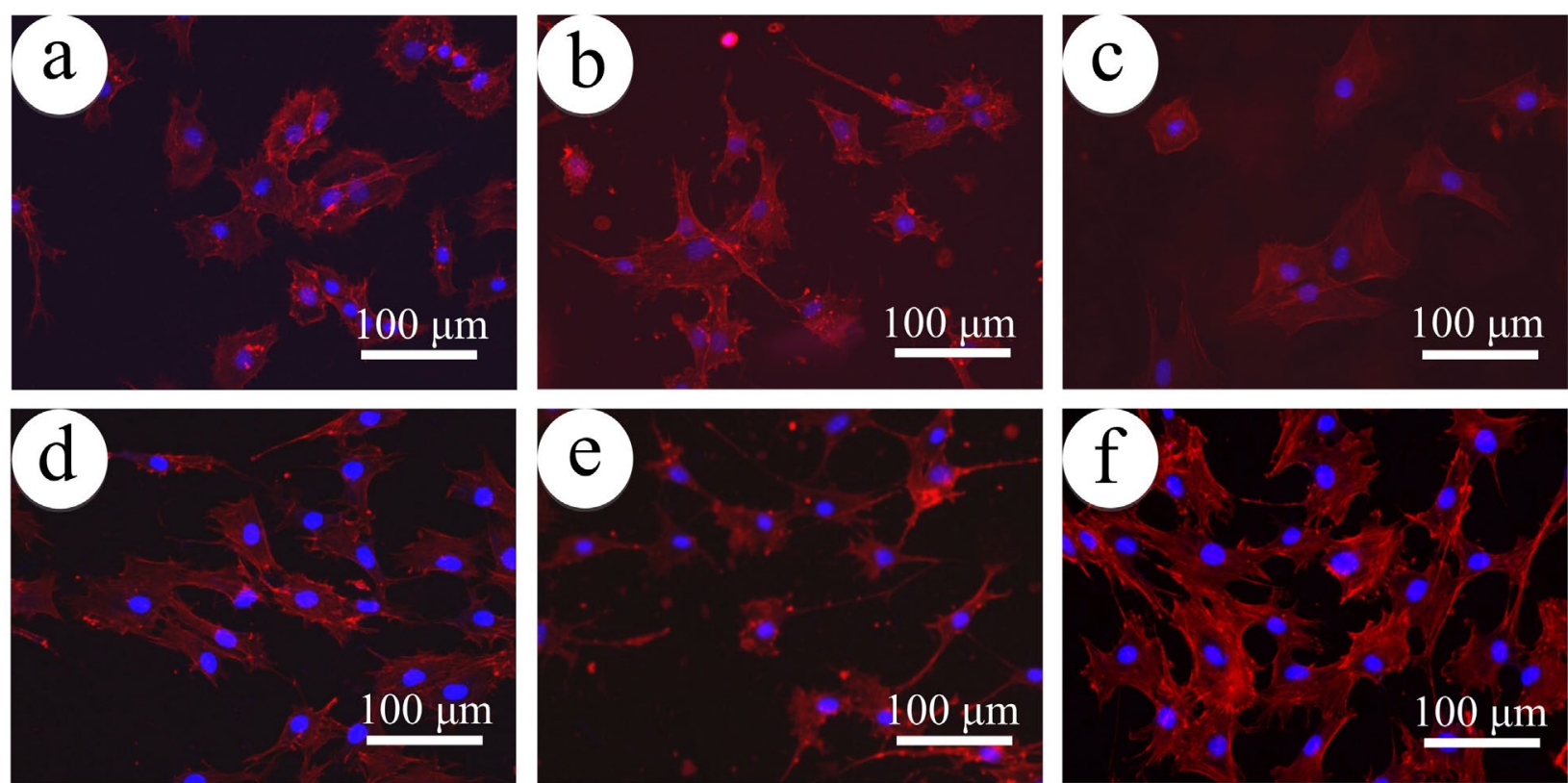

Fig. 6. Representative fluorescent images of mouse preosteoblasts cultured on various surfaces after 1 (a-c) and 3 days (d-f): EF (a, d), REF (b, e) and EFRM (c, f). The cells were stained with phalloidin-TRITC for F-actin (red) and DAPI for cell nuclei (blue). Scale bar $=100 \mu \mathrm{m}$.

Fig. 7. Metabolic activity of mouse preosteoblasts on various surfaces determined by MTT assay. Data presented from three individual experiments. * Statistically significant, $p<0.01$.

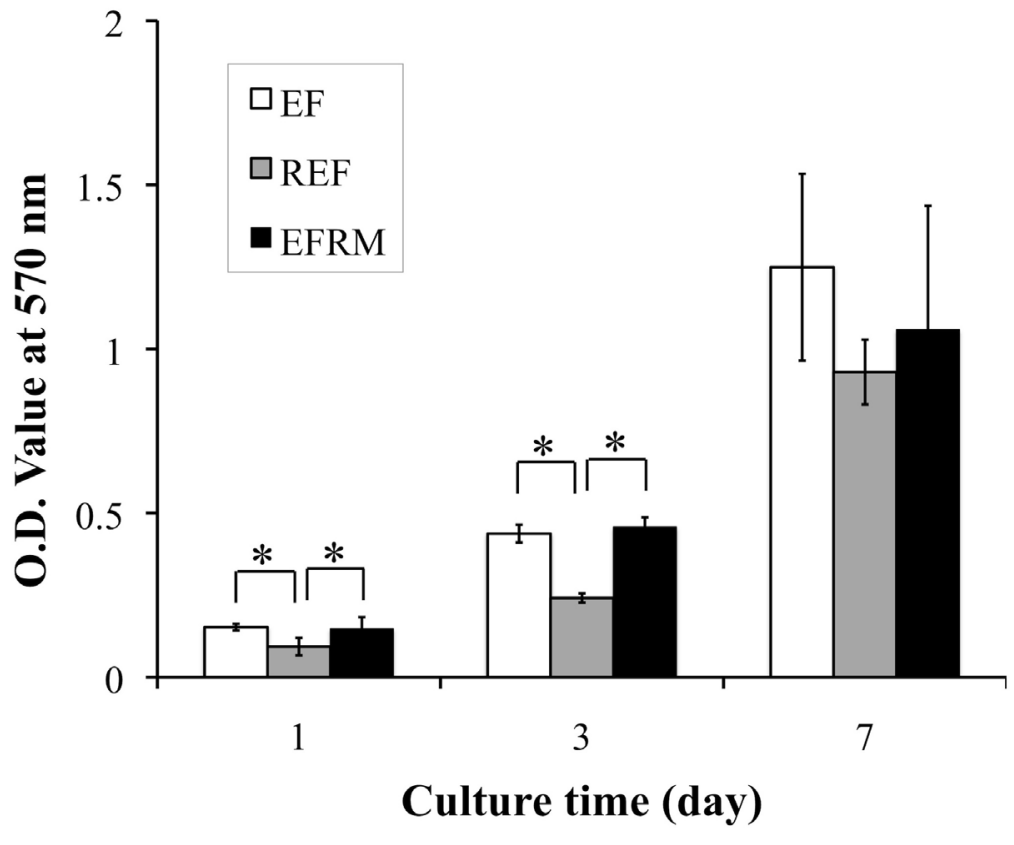

staining showed that only dead bacteria were detected in either REF or EFRM (red dots in Fig. 5h and i insets), while the large clump in EF controls contained a great quantity of live $S$. epidermidis as indicated by the intense green fluorescence in Fig. $5 \mathrm{~g}$. It is necessary to point out that the large and irregular fluorescent dots in Fig. 5h were artefacts from the beads formed during the electrospinning. The result of the agar-plating assay showed that no planktonic $S$. epidermidis was found in the supernatants of both REF and EFRM, while approximately $1.0 \times 10^{9} \mathrm{CFU} / \mathrm{mL} S$. epidermidis was detected from the Rf-free EF controls (Fig. 5c).

\section{Preosteoblast culture}

The fluorescent staining of the cellular cytoskeleton filament actin (F-actin) showed that distinct cell morphology was noticed among various substrates as early as day 1 . On both EF and EFRM, preosteoblasts began to adhere and spread in a polygonal morphology (Fig. 6a and c), while a constrained yet slim morphology (Fig. 6b) was consistently observed on the REF substrates even after 3-day culture (Fig. 6e). No noticeable difference could be identified between EF and EFRM. The MTT results $(n=3)$ showed that a significantly lower cell metabolic activity was measured in REF group at day 1 and 3 , in comparison to both EF and EFRM groups $(p<0.01)$, and the difference became less obvious by 7 days after media change. Consistent with the fluorescent staining result, cell metabolic activity between EF and EFRM was comparable at all the investigated time points (Fig. 7).

The RT-PCR results $(n=3)$ showed that no significant difference was found in OPN expression among all three 


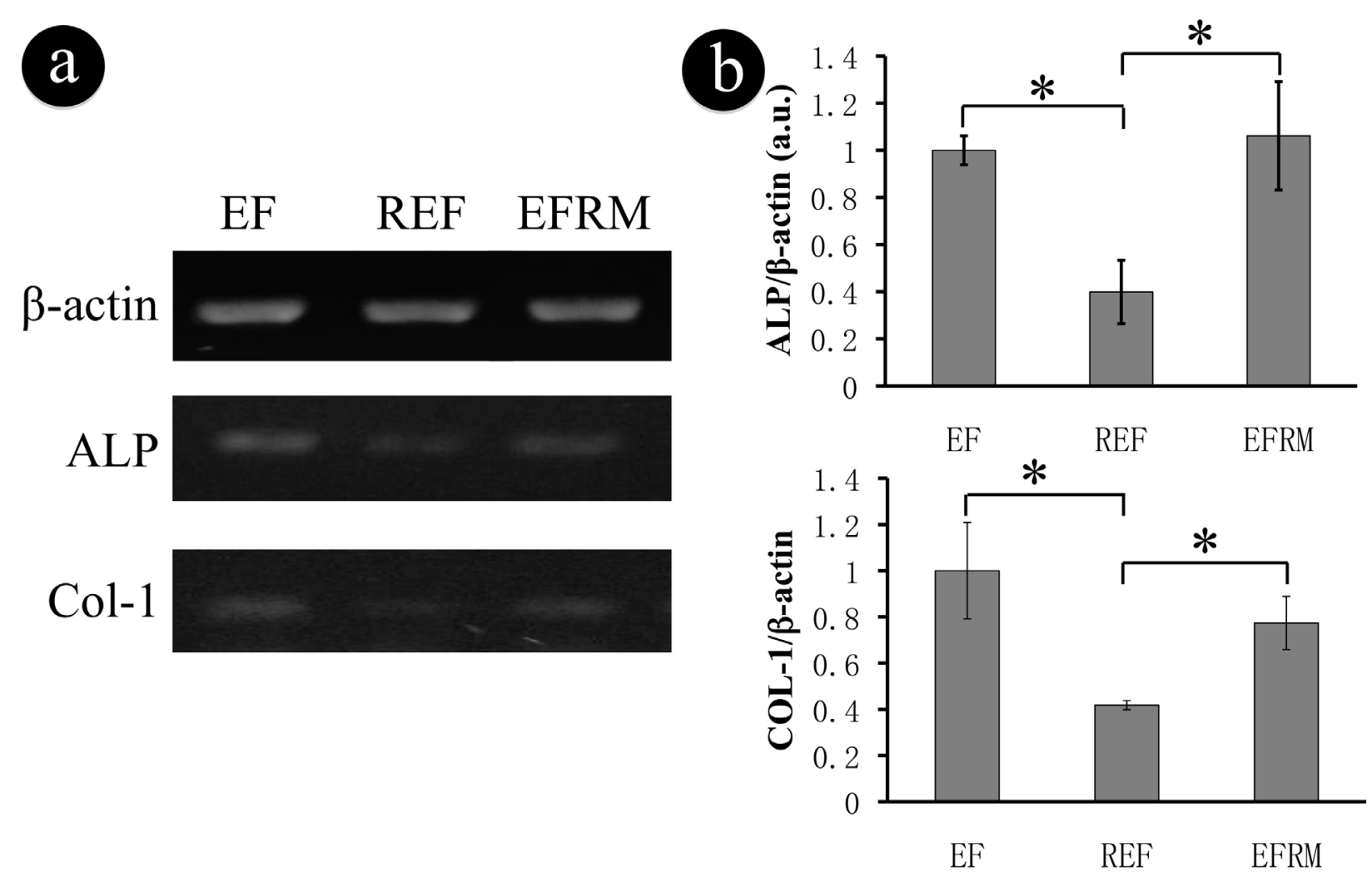

Fig. 8. Gene expression of osteogenic markers on various substrates (EF, REF and EFRM). Representative electrophoresis gel (a) and semi-quantitative analysis of gene expression (b). The data presented were normalised with $\beta$-actin. * Statistically significant, $p<0.01$.

groups (data not shown), however, the expression of both type I collagen (COL-1) and alkaline phosphatise (ALP) was noticeably lower on the REF substrates (Fig. 8a) and semi-quantification of the expression intensity confirmed this observation (Fig. 8b). No significant difference between EF and EFRM was measured in both ALP and COL-1 gene expression (Fig. 8).

\section{Discussion}

The failure of long-term orthopaedic implants has mainly resulted from bacterial infection and implant loosening due to poor adhesion to host bone tissue (Van de Belt et al., 2001; Neut et al., 2003; Campoccia et al., 2006), so the intrinsic competition between infectious bacteria and tissue-forming cells for implant surface determines the benefits to design a cell-adhesive, bacteria-repulsive surface. Multistep efforts were made to modify the titanium surface with covalently grafted chitosan, hyaluronic acid or their derivatives to suppress bacterial adhesion, and immobilise RGD peptide or growth factors to enhance osseointegration (Shi et al., 2008; Shi et al., 2009; Hu et al., 2010). However, these approaches involved not only two main chemical modification steps, but also several preparing and cleaning steps, which could potentially complicate its application by requiring a longer time and more chemicals to modify the titanium surface. In this regard, the present study was aimed to develop a simple and cost-effective strategy for modifying the implant surface with a similar multi-functionality and meanwhile applicability to a wider range of long-term orthopaedic implant substrates. Compared to previous efforts, the new approach only needed two steps, i.e., electrospinning and micro-pattern printing, which could be completed in several hours with a few economical chemicals. Thus, this approach can be readily translated into "clinically appropriate large scale production techniques" (Ozkan et al., 2009) with reproducibility and cost-effectiveness.

The advantages of electrospun PCL/chitosan nanofibres (EF) in promoting bone cell adhesion and differentiation have been highlighted as a result of their morphological similarity to native ECM fibrils and the presence of chitosan (Yang et al., 2009a). However, high bacterial adhesion to such nanofibrous meshes was also observed in the present study (Fig. 5a) and as reported previously (Wang et al., 2010). To address this challenge, the incorporation of antibiotics into nanofibres seems to be a plausible solution (Zeng et al., 2003; Liang et al., 2007; Sill and von Recum, 2008). By electrospinning the blended solutions containing a model antibiotic, $\mathrm{Rf}$, Rf-containing $\mathrm{PCL} /$ chitosan nanofibres with a similar diameter to pure PCL/chitosan nanofibres (Fig. 2d and 2e, Table 1) were produced. Theoretically, the lipophilic nature of $\mathrm{Rf}$ (Zeng et al., 2003) would allow a complete dissolution of $\mathrm{Rf}$ in the PCL/chitosan solution to form a homogeneous blended solution and therefore produce the nanofibres with evenly distributed Rf. Indeed, most of the Rf distributed 
uniformly across the PCL/chitosan nanofibre surface and it was confirmed by using a fluorescent substitute with comparable molecular weight, rhodamine 610 (Exciton, Dayton, OH, USA) (data not shown). However, a few large beads in dark red were also observed among the nanofibres (Fig. 2b inset and 2e). This may be ascribed to the possible binding of anionic RF with cationic chitosan to form complexes (Cao and Sun, 2009), which reduced the solution viscosity from $5.3 \times 10^{-2}$ (PCL/chitosan) to $4.9 \times 10^{-2} \mathrm{~kg} \mathrm{~m}^{-1} \mathrm{~s}^{-1}$ (PCL/chitosan/Rf) and affected the electrospinning process (Pham et al., 2006). The high surface area/volume ratio of nanofibres allowed a rapid release of Rf (Fig. 4), consistent with our previous observation with BSA release (Yang and Wang, 2010). Additionally, during electrospinning the fast solvent evaporation and the high ionic strength of Rf in the solution might lead to the distribution of Rf mainly on the surface of PCL/chitosan fibres (Fig. 2b), which consequently causes an initial burst release of Rf (Zeng et al. 2003; Kim et al., 2004; He et al., 2009).

Rapid release of $\mathrm{Rf}$ from PCL/chitosan fibres results in a high $\mathrm{Rf}$ concentration in the culture sufficient to kill $S$. epidermidis and prevent biofilm formation. Indeed, only individual $S$. epidermidis bacteria were observed in the Rf-containing nanofibres (Fig. 5e) and a majority of them were stained dead (Fig. 5h). It is necessary to mention that Rf may not be the best choice, however, it demonstrates its effectiveness as a model antibiotic to kill planktonic S. epidermidis of NJ9709 strain in this study, i.e., where it was incorporated into PCL/chitosan nanofibres (REF) or PLGA micro-patterns (EFRM), and it can be easily replaced with a better one or a cocktail due to the flexibility of our approach. Our previous study has shown a negligible toxicity of Rf to osteoblasts even up to $60 \mu \mathrm{g} / \mathrm{mL}$ (Lee et al., 2011), which is about two times higher than the maximum Rf concentration (i.e., $22.8 \mu \mathrm{g} / \mathrm{mL}$ ) released from REF or EFRM in this study. However, the homogeneous distribution of RF across PCL/chitosan nanofibres could change the surface properties of nanofibres (Fig. 3). Clearly, variation in surface properties would modulate the interactions between electrospun nanofibres and cell membrane integrin receptors (Huang et al., 2008; Tambralli et al., 2009; Kwei et al., 2010), which are closely associated with intracellular signalling, and therefore affects the cell metabolic activity and differentiation (Giancotti, 1999; Schwartz and Assoian, 2001). Indeed, the attachment and spreading of preosteoblasts on REF were noticeably different from those on EF (Fig. 6). Significantly lower cell metabolic activity was measured on REF for up to 3 days compared to EF meshes. Since Rf was completely released from the nanofibres after two days (Fig. 4), no Rf was left in the fibres after medium change on day 3 . As a result, the difference in cell metabolic activity on day 7 became less pronounced among all three groups (Fig. 7), further suggesting the unfavourable effect of $\mathrm{Rf}$ presented in the PCL/chitosan nanofibres. Similar results were also consistently observed with other tissue cells such as fibroblasts (data not shown). Moreover, it was confirmed that the presence of $\mathrm{Rf}$ in the PCL/chitosan nanofibres decreased the expression of osteogenic markers (Fig. 8).

To minimise the detrimental influence of $\mathrm{Rf}$ to the surface properties of PCL/chitosan nanofibres, it is possible to encapsulate $\mathrm{Rf}$ in the core to form core-shell nanofibres via coaxial electrospinning (Sun et al., 2003; Jiang et al., 2005; Zhang et al., 2007). However, prolonged processing and narrow drug loading capacity could be a challenge in adopting this technique, apart from the need of special setups (Maretschek et al., 2008).

Deposition of Rf-eluting PLGA micro-patterns on $\mathrm{PCL} /$ chitosan nanofibre meshes allows the incorporation of $\mathrm{Rf}$ onto the nanofibre substrate without changing the surface properties (Fig. 2). Different from the uniform distribution of Rf in REF fibres, Rf in PLGA micro-patterns disperses as discrete particles of $\sim 10-100 \mathrm{~nm}$ (Gu et al., 2012) as a result of the re-crystallisation of Rf with slow evaporation of DMSO during ink-jet patterning. The distinct appearance of Rf in REF and PLGA micro-patterns of EFRM probably contributes partially to the differential release profile of $\mathrm{Rf}$ as shown in Fig. 4. In addition, the slower Rf release from EFRM may also come from the fact that $\mathrm{Rf}$ particles were effectively embedded in PLGA micro-patterns and its release would greatly depend on the degradation kinetics of the PLGA matrix (Polakovic et al., 1999; Commandeur et al., 2006; Gu et al., 2012). In this regard, it is possible to decelerate the $\mathrm{Rf}$ release rate by utilising less hydrophilic PLGA or increasing the molecular weight of PLGA (Murakami et al., 2000). Although a slower Rf release rate was measured from the EFRM substrates (about $58.0 \%$ of REF in $1 \mathrm{~h}$ ), sufficient $\mathrm{Rf}$ was released within the first hour (much higher than MBC of $0.5 \mu \mathrm{g} / \mathrm{mL}$ ) to eradicate $S$. epidermidis and stunt biofilm formation. Earlier studies have demonstrated the necessity of rapidly releasing antibiotics within a few hours after surgery to efficiently eliminate the bacteria before they begin to proliferate (Bölgen et al., 2007; He et al., 2009; Yoo et al., 2009). The culture of preosteoblasts on EFRM substrates did not adversely affect the cellular response, and instead followed a similar pattern to those on the EF controls in terms of cell spreading, proliferation and differentiation (Fig. 6-8). The possible explanations to this are (1) the $75 \mu \mathrm{m}$ Rf-containing PLGA micropattern arrays deposited on the nanofibre meshes only take about $20 \%$ of the total surface area, and (2) the $150 \mu \mathrm{m}$ inter-micro-pattern distance is large enough for the preosteoblasts to attach, spread and proliferate onto the intact PCL/chitosan nanofibre surfaces. Considering that only one micro-pattern configuration was used in this study, our further efforts will focus on addressing whether reduced micro-pattern separation distances can affect the behaviour of preosteoblasts.

In this study, the effort to integrate biomimetic nanofibres with antibiotic-eluting micro-patterns for possible modification of orthopaedic implant surfaces was the first attempt to minimise infection and promote bone tissue formation. With the successful demonstration of the dual function, our continuous efforts will focus on the integration of such fibre meshes to implant surface. Interestingly, our initial measurement has shown a good bonding force between electrospun nanofibre meshes and smooth titanium alloy $\left(\mathrm{TiAl}_{6} \mathrm{~V}_{4}\right)$ substrates (the roughness is $\sim 0.05 \mu \mathrm{m}$ ) (data not shown), close to the strength of human bone ( $18 \mathrm{MPa})$ (Kar et al., 2006), suggesting its 
good resistance to mechanical disruption and potential use for implant surface. Furthermore, its application can also be extended to other possibilities, e.g., to modify other types of long-term implants by choosing appropriate nanofibres and drugs or to be used as wound dressing and surgical meshes.

\section{Conclusions}

For those long-term orthopaedic implants, the design of a multifunctional surface to minimise infection while supporting tissue formation represents a promising paradigm. In recognition of the stimulatory effect of PCL/ chitosan biomimetic nanofibres on tissue formation, the incorporation of antibiotics (e.g., Rf) to nanofibre meshes for infection control may achieve the desired multifunctionality. In this study, deposition of Rf-containing PLGA micro-patterns ( $75 \mu \mathrm{m}$ in diameter and $\sim 150 \mu \mathrm{m}$ apart) onto PCL/chitosan electrospun nanofibres yield a multifunctional substrate, which can effectively kill S. epidermidis and prevent biofilm formation without sacrificing the osteogenic properties of PCL/chitosan nanofibres. Taken together, the present study provides further evidence to the emerging efforts in designing multifunctional surfaces for enhancing bone tissue formation while controlling infection.

\section{Acknowledgements}

This investigation was sponsored by the Biomedical Engineering and Biomaterials program of the National Science Foundation (CBET 1033742 and DMR 1005902). Xuening Chen is also partially supported by Innovation \& Entrepreneurship Doctoral Fellowship from Stevens Institute of Technology.

\section{References}

Alt V, Bitschnau A, Osterling J, Sewing A, Meyer C, Kraus R, Meissner SA, Wenisch S, Domann E, Schnettler R (2006) The effects of combined gentamicin-hydroxyapatite coating for cementless joint prostheses on the reduction of infection rates in a rabbit infection prophylaxis model. Biomaterials 27: 4627-4634.

Banerjee I, Ravindra CP, Ravi SK (2011) Antifouling coatings: recent developments in the design of surfaces that prevent fouling by proteins, bacteria, and marine organisms. Adv Mater 23: 690-718.

Bearinger JP, Terrettaz S, Michel R, Tirelli N, Vogel H, Textor M, Hubbell JA (2003) Chemisorbed poly (propylene sulphide)-based copolymers resist biomolecular interactions. Nat Mater 2: 259-264.

Bölgen N, Vargel I, Korkusuz P, Menceloğlu YZ, Pişkin $\mathrm{E}$ (2007) In vivo performance of antibiotic embedded electrospun PCL membranes for prevention of abdominal adhesions. J Biomed Mater Res B: Appl Biomater 81: 530-543.

Campoccia D, Lucio M, Arciola CR (2006) The significance of infection related to orthopedic devices and issues of antibiotic resistance. Biomaterials 27: 2331-2339.
Cao Z, Sun Y (2009) Chitosan-based rechargeable long-term antimicrobial and biofilm-controlling systems. J Biomed Mater Res A 89: 960-967.

Commandeur S, van Beusekom HM, van der Giessen WJ (2006) Polymers, drug release, and drug-eluting stents. J Intervent Cardiol 19: 500-506.

Giancotti FG (1999) Integrin signaling. Science 285: 1028-1033.

Gristina AG (1987) Biomaterial-centered infection: Microbial adhesion versus tissue integration. Science 237: 1588-1595.

Gu YX, Chen XN, Lee JH, Monteiro DA, Wang HJ, Lee WY (2012) Inkjet-printed antibiotic- and calciumeluting bioresorbable nanocomposite micro-patterns for orthopaedic implants. Acta Biomater 8: 424-431.

Hamade RF, Zeineddine F, Akle B, Smaili A (2005) Modelangelo: a subtractive 5-axis robotic arm for rapid prototyping. Robotics Computer-Integr Manufact 21: 133144.

Hayes JS, Vos DI, Hahn J, Pearce SG, Richards RG (2009) An in vivo evaluation of surface polishing of Tan intermedullary nails for ease of removal. Eur Cell Mater 18: $15-26$.

Hayes JS, Seidenglanz U, Pearce AI, Pearce SG, Archer CW, Richards RG (2010) Surface polishing positively influences ease of plate and screw removal. Eur Cell Mater 19: 117-126.

Hayes JS, Welton JL, Wieling R, Richards RG (2012) In vivo evaluation of defined polished titanium surfaces to prevent soft tissue adhesion. Journal of Biomedical Materials Research Part B, Applied Biomater 100: 611-617.

He CL, Huang ZM, Han XJ (2009) Fabrication of drug-loaded electrospun aligned fibrous threads for suture applications. J Biomed Mater Res A 89: 80-95.

$\mathrm{Hu}$ XF, Neoh KG, Shi ZL, Kang ET, Poh C, Wang W (2010) An in vitro assessment of titanium functionalized with polysaccharides conjugated with vascular endothelial growth factor for enhanced osseointegration and inhibition of bacterial adhesion. Biomaterials 31: 8854-8863.

Huang C, Fu X, Liu J, Qi Y, Li S, Wang H (2012) The involvement of integrin $\beta 1$ signaling in the migration and myofibroblastic differentiation of skin fibroblasts on anisotropic collagen-containing nanofibers. Biomaterials 33: 1791-1800.

Huang Z, Sargeant TD, Hulvat JF, Mata A Jr, Pablo B, Koh C, Stupp SI, Snead ML (2008) Bioactive nanofibers instruct cells to proliferate and differentiate during enamel regeneration. J Bone Miner Res 23: 1995-2006.

Jiang HL, Hu YQ, Li Y, Zhao PC, Zhu KJ, Chen WL (2005) A facile technique to prepare biodegradable coaxial electrospun nanofibers for controlled release of bioactive agents. J Control Rel 108: 237-243.

Kaplan JB, Ragunath C, Velliyagounder K, Fine DH, Ramasubbu N (2004) Enzymatic detachment of Staphylococcus epidermidis biofilms. Antimicrob Agents Chemother 48: 2633-2636.

Kar A, Raja KS, Misra M (2006) Electrodeposition of hydroxyapatite onto nanotubular $\mathrm{TiO} 2$ for implant applications. Surf Coat Technol 201: 3723-3731.

Katti DS, Robinson KW, Ko FK, Laurencin CT (2004) Bioresorbable nanofiber-based systems for wound healing 
and drug delivery: optimization of fabrication parameters. J Biomed Mater Res B: Applied Biomater 70: 286-296.

Kenawy E, Bowlin GL, Mansfield K, Layman J, Simpson DG, Sanders EH, Wnek GE (2002) Release of tetracycline hydrochloride from electrospun poly(ethyleneco-vinylacetate), poly(lactic acid), and a blend. J Control Rel 81: 57-64.

Kim K, Luu YK, Chang C, Fang DF, Hsiao BS, Chu B, Hadjiargyrou M (2004) Incorporation and controlled release of a hydrophilic antibiotic using poly(lactideco-glycolide)-based electrospun nanofibrous scaffolds. J Control Rel 98: 47-56.

Kwei SP, Moffat KL, Levine WN, Lu HH (2010) Nanofiber alignment regulates adhesion and integrin expression of human mesenchymal stem cells and tendon fibroblasts. Proc 2010 IEEE 36th Ann Northeast Bioeng Conf (NEBEC) 14: 1-2.

Lee JH, Kaplan JB, Lee WY (2011) Microfluidic approach to create $3 \mathrm{D}$ tissue models biofilm related infection of orthopaedic implants. Tissue Eng C Meth 17: 39-48.

Liang DH, Hsiao BS, Chu B (2007) Functional electrospun nanofibrous scaffolds for biomedical applications. Adv Drug Del Rev 59: 1392-1412.

Lucke M (2003) Gentamicin coating of metallic implants reduces implant-related osteomyelitis in rats. Bone 32: 521-531.

Maretschek S, Greiner A, Kissel T (2008) Electrospun biodegradable nanofiber nonwovens for controlled release of proteins. J Control Rel 127: 180-187.

Monzon M, Oteiza C, Leiva J, Amorena B (2001) Synergy of different antibiotic combinations in biofilms of Staphylococcus epidermidis. J Antimicrob Chemother 48:793-801.

Moriarty TF, Debefve L, Boure L, Campoccia D, Schlegel U, Richards RG (2009) Influence of material and microtopography on the development of local infection in vivo: experimental investigation in rabbits. Int J Artific Org 32: $663-670$.

Moriarty TF, Campoccia D, Nees SK, Boure LP, Richards RG (2010) In vivo evaluation of the effect of intramedullary nail microtopography on the development of local infection in rabbits. Int J Artific Org 33: 667-675.

Murakami H, Kobayashi M, Takeuchi H, Kawashima Y (2000) Utilization of poly(DL-lactide-co-glycolide) nanoparticles for preparation of mini-depot tablets by direct compression. J Control Rel 67: 29-36.

Neut D, van Horn JR, van Kooten TG, van der Mei $\mathrm{HC}$ and Busscher HJ (2003) Detection of biomaterialassociated infections in orthopaedic joint implants. Clin Orthopaed Rel Res 413: 261-268.

O’Reilly T, Kunz S, Sande E, Zak O, Sande MA, Tauber MG (1992) Relationship between antibiotic concentration in bone and efficacy of treatment of staphylococcal osteomyelitis in rats: azithromycin compared with clindamycin and rifampin. Antimicrob Agents Chemother 36: 2693-2697.

Otto DP, Vosloo HC, Liebenberg W, de Villiers MM (2008) Development of microporous drug-releasing films cast from artificial nanosized latexes of poly(styrene- co-methyl methacrylate) or poly(styrene-co-ethyl methacrylate). Eur J Pharm Biopharm 69: 1121-1134.

Ozkan S, Kalyon DM, Yu XJ, Mckelvey CA, Lowinger M (2009) Multifunctional protein-encapsulated polycaprolactone scaffolds: Fabrication and in vitro assessment for tissue engineering. Biomaterials 30: 43364347.

Pham QP, Sharma U and Mikos AG (2006) Electrospinning of polymeric nanofibers for tissue engineering application: a review. Tissue Eng 12: $1197-$ 1211.

Polakovic M, Gorner T, Gref R, Dellacherie E (1999) Lidocaine loaded biodegradable nanospheres. II. Modelling of drug release. J Control Rel 60: 169-177.

Radin S, Ducheyne P (2007) Controlled release of vancomycin from thin sol-gel films on titanium alloy fracture plate material. Biomaterials 28: 1721-1729.

Schindler M, Ahmed I, Kamal J, Nur-E-Kamal A, Grafe TH, Chung HY, Meiners S (2005) A synthetic nanofibrillar matrix promotes in vivo-like organization and morphogenesis for cells in culture. Biomaterials 26: 5624-5631.

Schwartz MA, Assoian RK (2001) Integrins and cell proliferation: regulation of cyclin-dependent kinases via cytoplasmic signaling pathways. J Cell Sci 114: 2553-2560.

Shasha B, Lang R, Rubinstein E (1994) Efficacy of combinations of doxycycline and rifampicin in the therapy of experimental mouse brucellosis. J Antimicrob Chemother 33: 545-551.

Shi ZL, Neoh KG, Kang ET, Poh C, Wang W (2008) Bacterial adhesion and osteoblast function on titanium with surface-grafte chitosan and immobilized RGD peptide. J Biomed Mater Res A 86: 865-872.

Shi ZL, Neoh KG, Kang ET, Poh C, Wang W (2009) Surface functionalization of titanium with carboxymethyl chitosan and immobilized bone morphogenetic protein-2 for enhanced osseointegration. Biomacromolecules 10: 1603-1611.

Sieuwerts AM, Klijn JG, Peters HA, Foekens JA (1995) The MTT tetrazolium salt assay scrutinised: how to use this assay reliably to measure metabolic activity of cell cultures in vitro for the assessment of growth characteristics, IC50values and cell survival. Eur J Clin Chem Clin Biochem 33: $813-823$.

Sill TJ, von Recum HA (2008) Electrospinning: applications in drug delivery and tissue engineering. Biomaterials 29: 1989-2006.

Silverstein RM, Webster FX (1997) Spectrometric Identification of Organic Compounds, 6th Ed. John Wiley \& Sons, Hoboken, NJ, pp 101.

Sun Z, Zussman E, Yarin AL, Wendorff JH, Greiner A (2003) Compound Core-Shell Polymer Nanofibers by Co-Electrospinning. Adv Mater 15: 1929-1932.

Tambralli A, Blakeney B, Anderson J, Kushwaha M, Andukuri A, Dean D, Jun HW (2009) A hybrid biomimetic scaffold composed of electrospun polycaprolactone nanofibers and self-assembled peptide amphiphile nanofibers. Biofabrication 1: 025001.

van de Belt H, Neut D, Schenk W, van Horn JR, van der Mei HC, Busscher HJ (2001) Infection of orthopedic 
implants and the use of antibiotic-loaded bone cements. A review. Acta Orthopaed Scand 72: 557-571.

Venugopal JR, Zhang Y, Ramakrishna S (2006) In vitro culture of human dermal fibroblasts on electrospun polycaprolactone collagen nanofibrous membrane. Artif Org 30: 440-446.

Wang C, Yang F, Zhang H (2010) Fabrication of non-woven composite membrane by chitosan coating for resisting the adsorption of proteins and the adhesion of bacteria. Separ Purif Technol 75: 358-365.

Yang XC, Wang HJ (2010) Electrospun functional nanofibrous scaffolds for tissue engineering. In: Tissue Engineering (Eberli D, ed), Intech, New York, pp 159-178,

Yang XC, Chen XN, Wang HJ (2009a) Acceleration of osteogenic differentiation of preosteoblastic cells by chitosan containing nanofibrous scaffolds. Biomacromolecules 10: 2772-2778.

Yang XC, Shah JD, Wang HJ (2009b) Nanofiber enabled layer-by-layer approach toward three-dimensional tissue formation. Tissue Eng A 15: 945-956.

Yin Z, Chen X, Chen JL, Shen WL, Nguyen TMH, Gao L, Ouyang HW (2010) The regulation of tendon stem cell differentiation by the alignment of nanofibers. Biomaterials 31: 2163-2175.

Yoo HS, Kim TG, Park TG (2009) Surfacefunctionalized electrospun nanofibers for tissue engineering and drug delivery. Adv Drug Del Rev 61: 1033-1042.

Zeng J, Xu XY, Chen XS, Liang QZ, Bian XC, Yang LX, Jing XB (2003) Biodegradable electrospun fibers for drug delivery. J Control Rel 92: 227-231.

Zhang YZ, Su B, Venugopal J, Ramakrishna S, Lim CT (2007) Biomimetic and bioactive nanofibrous scaffolds from electrospun composite nanofibers. Int J Nanomedicine 1: 623-638.

Zimmerli W, Widmer AF, Blatter M, Frei R, Ochsner PE (1998) Role of rifampin for treatment of orthopedic implant-related staphylococcal infections. J Am Med Ass 279: $1537-1541$.

Zimmerli W, Trampuz A, Ochsner PE (2004) Prosthetic-joint infections. N Engl J Med 351:1645-1654.

Zong X, Li S, Chen E, Garlick B, Kim KS, Fang D, Chiu J, Zimmerman T, Brathwaite C, Hsiao BS, Chu B (2004) Prevention of postsurgery-induced abdominal adhesions by electrospun bio- absorbable nanofibrous poly(lactide-co-glycolide)-based membranes. Ann Surg 240: $910-925$.

\section{Discussion with Reviewers}

Reviewer I: Can the authors extend on the possible use of these meshes?

Authors: Yes. Although in this study nanofibre meshes with antibiotic-eluting micro-patterns are primarily used to modify the orthopaedic implant surfaces for minimising infection and promoting bone tissue formation, their application can be extended to other possibilities, e.g., to modify other types of implants by choosing the appropriate nanofibres and drugs or to be used as wound dressing and surgical meshes.

Reviewer II: How would you compare the findings of your study to other methods for creating a functionalised surface? What are the potential advantages and disadvantages of your proposed method compared to other described methods?

Authors: Considering the primary objective of this study to achieve a dual functional surface, i.e., preventing infection while promoting osteogenesis, printing of antibioticeluting PLGA micro-patterns onto PCL/chitosan nanofibre meshes proves to be effective in eliminating the model $S$. epidermidis strain without sacrificing the osteogenic feature of PCL/chitosan nanofibres. Actually, this strategy has the flexibility to choose a single or a cocktail of antibiotics to be included in the micro-patterns and to configure the biomimetic nanofibres to be tissue specific. Compared to those efforts in modifying the surface either for infection control or for tissue formation (Bearinger et al., 2003; Alt et al., 2006; Banerjee et al., 2011, text references), clearly the dual functions as addressed would be superior. Additionally, this approach is rather straightforward and cost-effective, overcoming the technical challenge and complexity confronted with chemical modification of the surfaces, which quite often is surface specific (Shi et al., 2008; Shi et al., 2009; He et al., 2010, text references). Meanwhile, this method can be applied to a wide range of implant substrates and has the potential to be used as wound dressing and surgical meshes depending on the mechanical strength of fibre meshes.

Reviewer III: In the introduction the authors mention that more cost-effective approaches are preferred. Can they explain why the nanofibres in combination with printed pattern will be more cost effective than other methods?

Authors: Nanofibres have shown their advantages in promoting cell adhesion and spreading, which may limit the need of growth factors or cytokines. Meanwhile, the simple setup and low cost to fabricate nanofibres via electrospinning represent another promising dimension for rapid translation to application. Incorporation of antibiotics into PLGA micro-patterns allows precise control of the amount of antibiotics for delivery by manipulating the size of micro-patterns and the inter-micro-pattern distance. In addition, a low amount of antibiotics is needed for local delivery compared to systematic administration. Compared to other efforts to produce multifunctional surfaces, e.g., functionalisation of titanium substrates with covalently grafted chitosan, hyaluronic acid or their derivatives for suppressing bacterial adhesion, and with immobilised RGD or growth factors for enhancing osseointegration (Hu et al., 2010; Shi et al., 2008; Shi et al., 2009, text references), which always require more steps (chemical modification and rinsing steps) and longer preparation time (a few days), the reported approach simply composes two steps (electrospinning and printing) and can be completed within a few hours. The simplified operations may allow the use of robotics to further improve the efficiency and lower the cost. 